\title{
Pseudomixoma peritoneal de origem apendicular: uma entidade rara
}

\author{
Pseudomyxoma peritonei of appendiceal origin: a rare entity
}

Mulher de 66 anos, observada por dor na fossa ilíaca direita com um ano de evolução, agravada nos seis meses anteriores e aumento do perímetro abdominal. Tinha antecedentes de histerectomia com anexectomia bilateral por neoplasia benigna do ovário e útero miomatoso. Apresentava um abdómen tenso, doloroso à palpação superficial e profunda, sem defesa. 0 estudo do tubo digestivo (endoscopia e colonoscopia) não revelou alterações. Realizou tomografia computadorizada (TC) abdominal, compatível com mucocelo apendicular (figuras 1 e 2). Na laparotomia exploradora verificou-se disseminação peritoneal extensa (figura 3).

0 mucocelo do apêndice é uma entidade rara, representando 0,3a $0,7 \%$ de todas as patologias do apêndice cecal e $8 \%$ dos tumores apendiculares ${ }^{1,2}$. Caracteriza-se pela acumulação de material mucinoso no lúmen apendicular, com evolução geralmente insidiosa e recorrente. A apresentação clínica é inespecifica, sendo frequentemente encontrados como achado acidental durante a exploração cirúrgica abdominal ou como dor e/ou massa palpável na fossa ilíaca direita ${ }^{3}$. Cerca de 10 a 15\% dos casos evoluem para pseudomixoma peritoneal (PMP), por ruptura do apêndice, com difusão de material gelatinoso na cavidade abdominal e pélvica e implantes peritoneais mucinosos ${ }^{1,2}$, condicionando o prognóstico. A opção terapêutica por excisão da lesão primária, cirurgia citorredutora, quimioterapia intrabdominal hipertérmica ou quimioterapia sistémica depende do estádio da doença. No caso apresentado, a presença de extensa carcinomatose peritoneal e o estado funcional da doente condicionou uma terapêutica mais agressiva, encontrando-se actualmente sob quimioterapia paliativa com FOLFOX simplificado. 0 prognóstico do PMP é reservado com taxa de sobrevivência a 5 anos de $81 \%$ e a 10 anos de apenas $32 \%{ }^{4}$.

\section{Referencias}

1. Ruiz-Tovar J, García Teruel D, Morales Castiñeiras V, Sanjuanbenito Dehesa A, López Quindós P, Martínez Molina E. Mucocele of the appendix. World J Surg. 2007; 31: $542-8$

2. Panarelli NC, Yantiss RK. Mucinous neoplasms of the appendix and peritoneum. Arch Pathol Lab Med. 2011; 135:1261-8

3. García Lozano A, Vázquez Tarrago A, Castro García C, Richart Aznar J, Gómez Abril S, Martínez Abad M. Mucocele apendicular: presentación de 31 casos. Cir Esp. 2010; 87(2):108-12

4. Quadrado C, Marques T, Bastos C, Pseudo-mixoma peritonal: caso clínico e revisão teórica. Minerva. 2010; 12(6):27-30

\section{Diagnóstico:}

Pseudomixoma peritoneal de origem apendicular

\section{Filipe Breda, Ana Carlos Bento}

Serviço de Medicina Interna, Hospitais da Universidade de Coimbra, Centro Hospitalar e Universitário de Coimbra, EPE. Coimbra. Portugal

Correspondencia: filipebreda82@gmail.com

Como citar este artículo: Breda F, Carlos Bento A.

Pseudomixoma peritoneal de origem apendicular: uma entidade rara. Galicia Clin 2014; 75 (3): 150

Recibido: 13/02/2014; Aceptado: 09/04/2014
Figura 1. Tomografia abdominal: mucocelo apendicular com calcificação parietal

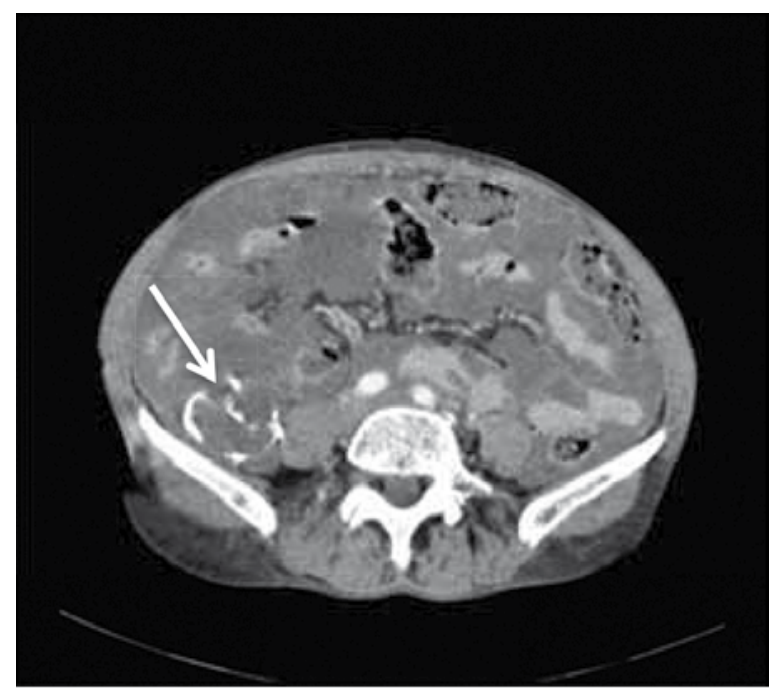

Figura 2. Tomografia abdominal: entalhe do contorno das ansas do delgado

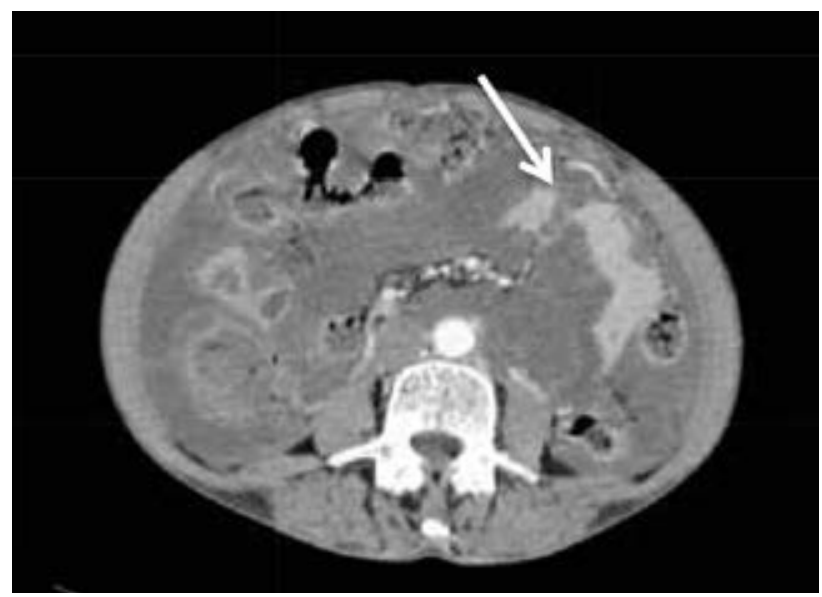

Figura 3. Biópsia do peritoneu (H\&E 40x): envolvimento do peritoneu por lagos de muco com ninhos de adenocarcinoma mucinoso de alto grau

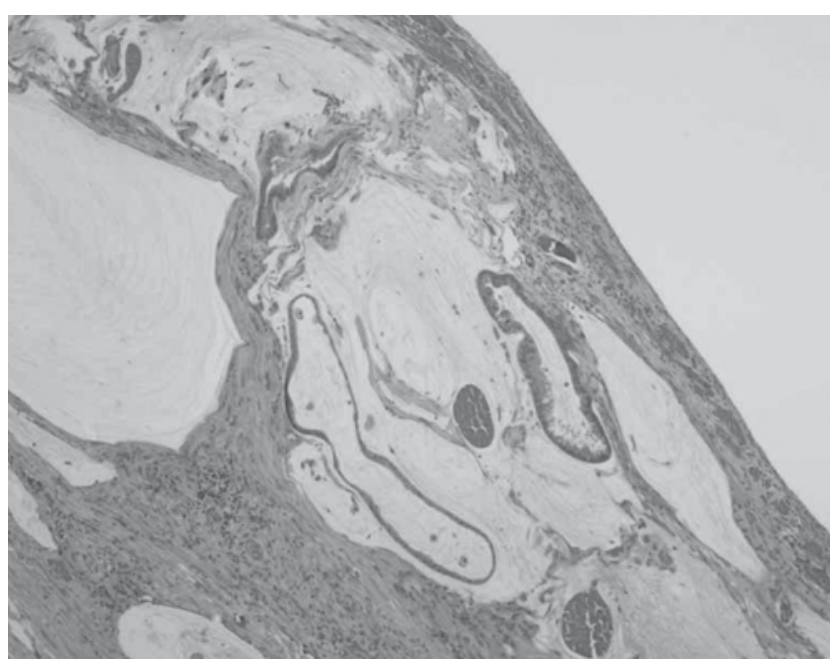

